\title{
Evaluation of COVID-19 Disease Awareness and Its Relation to Mental Health, Dietary Habits, and Physical Activity: A Cross-Sectional Study from Pakistan
}

\author{
Ahmad Ali, ${ }^{1} \dagger$ Muhammad Sohaib, ${ }^{1 *}$ Sanaullah lqbal, ${ }^{1}$ Khezar Hayat, ${ }^{2,3} \dagger$ Azmat Ullah Khan, ${ }^{1}$ and Muhammad Fawad Rasool ${ }^{4}$ \\ ${ }^{1}$ Department of Food Science and Human Nutrition, Faculty of Biosciences, University of Veterinary and Animal Sciences, Lahore, Pakistan; \\ ${ }^{2}$ Department of Pharmacy Administration and Clinical Pharmacy, School of Pharmacy, Xi'an Jiaotong University, Xi'an, China; ${ }^{3}$ Institute of \\ Pharmaceutical Sciences, University of Veterinary and Animal Sciences, Lahore, Pakistan; ${ }^{4}$ Department of Pharmacy Practice, Faculty of \\ Pharmacy, Bahauddin Zakariya University, Multan, Pakistan
}

\begin{abstract}
Coronavirus infection (COVID-19) has significantly increased the mortality and morbidity rates worldwide. The present study was conducted to assess the general public's awareness of COVID-19 and its association with mental health, dietary habits, and physical activity. A web-based survey was conducted to gather information about demographics, knowledge about COVID-19, dietary habits, mental health, and anthropometry among the general public of Pakistan. Descriptive statistics, chi-square test, and multiple logistic regression were used for data analysis. The majority of the participants were suffering from anxiety (71.0\%) and depression (52.0\%) during the COVID-19 pandemic; $32.4 \%$ of participants had poor COVID-19-related knowledge. COVID-19 lockdown reduced the physical activity of $66.9 \%$ of participants and increased weight of $38.8 \%$ of the survey participants. Demographic variables, including age, gender, ethnicity, education, employment, family type, and geographical location, were significantly associated with knowledge about COVID-19 $(P<0.05)$. Depression was inversely associated with COVID-19 knowledge $(P<0.05)$. Healthy changes in dietary habits including decreased consumption of fast foods, soft and cola drinks, fruit drinks, cooked meat (outside the home), sugar, and fats, and were associated with increased knowledge of COVID-19. Vitamin C and immunityboosting supplement consumption were significantly associated with increased knowledge regarding COVID-19 (<0.05). Inadequate knowledge about COVID-19 and the presence of anxiety and depression were found among most of the study participants. There is a need to conduct educational seminars to limit the health consequences resulting from COVID-19 lockdown.
\end{abstract}

\section{INTRODUCTION}

SARS-CoV-2 is a novel coronavirus causing COVID-19. The initial cases of COVID-19 were reported in Wuhan, China, and afterward, it spread rapidly worldwide, affecting nearly 213 countries within 2-3 months. ${ }^{1,2}$ The WHO reported $105,737,348$ cases of COVID-19 worldwide, with 2,302,976 deaths as of February 5, 2021. In Pakistan, the first case of COVID-19 was confirmed on February 26, 2020, which spread across the country. At the time of writing, there were 551,842 laboratory-confirmed cases of COVID-19 coupled with 11,886 deaths. ${ }^{3}$ On March 11, 2020, the WHO declared the COVID-19 outbreak as a global pandemic because of its spread in various countries and China. ${ }^{4}$

The most common symptoms of COVID-19 include breathing difficulties, dry cough, fever, and kidney failure. The risk of catching the infection was highest in the elderly or persons with comorbidities, including diabetes, cardiovascular disease, and lung disease. ${ }^{5}$

There is a need to flatten the curve of COVID-19 by restricting its transmission, which will also avoid economic deuteriation. The transmission can be reduced by following general hygienic principles, including frequent handwashing with soap or sanitizers, the use of face masks or personal protective equipment, and to avoid attending public gathering. ${ }^{6}$ Numerous countries have opted for specific strategies such as contact tracing, quarantine of infected persons at home or healthcare facility, restricting mass movement and gatherings, use of print and electronic media to spread the

\footnotetext{
*Address correspondence to Muhammad Sohaib, Department of Food Science and Human Nutrition, Faculty of Biosciences, University of Veterinary and Animal Sciences, outfall Rd., Lahore 54000, Pakistan. E-mail: muhammad.sohaib@uvas.edu.pk

$\dagger$ These two authors contributed equally.
}

information on social distancing, personal hygiene, preparation of health facilities with mechanical ventilation, isolation wards, and oxygen therapy for critically ill patients to tackle this COVID-19 pandemic. ${ }^{1,7}$

Dietary factors and healthy eating habits play a crucial role in human health management. The global pandemic of COVID19 has significantly changed the dietary patterns and eating habits of the people worldwide, particularly in the area affected by this pandemic. ${ }^{8,9}$ During the COVID-19 pandemic, there is an urgent need to expand public health activities beyond direct clinical management to cover basic principles of management and optimization of resource utilization, especially in terms of nutrition and dietary habits, for mitigating the impact of a pandemic on human health. ${ }^{10}$ Therefore, it is vital to determine and change people's conceptions and knowledge regarding healthy dietary habits for maintaining the health status of the peoples in a pandemic.

After the declaration of the COVID-19 pandemic, a lot of information regarding prevention, transmission, and personal hygiene flooded into conventional and social media. The influx of misinformation in the media could negatively affect a person's mental health due to the continuous fear of being infected. ${ }^{11}$ Lockdown secondary to the COVID-19 pandemic has socially disconnected people, and social disconnectedness is strongly linked to anxiety and depression. ${ }^{12}$ Dietary pattern is also strongly associated with anxiety and depression status of people as dietary intake can be affected by the disease, socioeconomic status, behaviors, emotions, and cultural pressures. ${ }^{13}$ Furthermore, changes in the dietary pattern can affect the physical activity and anthropometric measurements of a person. Social connectedness, dietary patterns, anxiety, and depression are linked to one another, and the change in the environment can significantly influence these parameters. ${ }^{14}$ 
In the past few decades, there is a change observed in the dietary patterns throughout the world, moving from natural foods to processed foods rich in animal fat, animal protein, refined carbohydrates, and sugars with a very minute quantity of dietary fiber. ${ }^{15}$ This shift in dietary patterns has tremendously increased the prevalence of autoimmune, inflammatory, and noncommunicable chronic diseases. ${ }^{16,17}$ The consumption of a diet high in fats, refined sugars, and trans fats can contribute to the obesity pandemic. Low-grade systemic inflammation can increase in obese patients. These diary changes can alter the gut microbiota composition, leading to gut dysbiosis. Gut dysbiosis is associated with increased intestinal permeability and pathogenic entry, and can lead to enhanced immune cell activation in adipose tissue and inflammatory response. Diet-induced obesity can lead to poor monocyte maturation and neutrophil dysfunction in bone marrow tissues. The compromised immune cells are associated with increased severity of pneumonia and acute lung injury. Hence, the relation between diet quality and immunity is robust. ${ }^{18}$ Therefore, the present study was conducted to assess the knowledge of COVID-19 disease and its association with anxiety, depression, dietary habits, and physical activity during the COVID-19 lockdown.

\section{MATERIALS AND METHODS}

Study design and setting. The present study was a descriptive cross-sectional survey conducted in the Punjab Province of Pakistan. This province was selected because more than half of the population of Pakistan live in Punjab, and it is the most developed province of Pakistan. The present study was conducted and reported following the instructions described in ref. 19.

Sample size calculation. The sample size was calculated by keeping the level of confidence at $99 \%$ and the level of precision at $5 \%$, and the anticipated frequency of the target population was set on $50 \%$ as the target population proportion from the total population was unknown. The total sample calculated for the present study was $664 .^{20}$

Adults between the ages of 18-65 years were asked about COVID-19, anxiety and depression, changes in dietary habits, and physical activity during the COVID-19 pandemic. Only participants living in Punjab were included in this study.

Data collection tools. An in-depth literature survey was undertaken to design a well-structured questionnaire. $3,11,18,21,22$ The initial version of the questionnaire was reviewed and validated by an expert panel of three professors of relevant background and two bilingual experts. Minor modifications were made to improve the understanding of the respondents as per the recommendations of the experts. There were four sections to this questionnaire. The components of the first section included demographic data such as age, gender, education, family income, and family type. The second section determined anxiety and depression by using Pakistan Anxiety and Depression Questionnaire, which is already validated in the Pakistani population. ${ }^{23}$ For each question, " 0 " was coded for positive and " 1 " was coded for a negative response. A total score of six or more indicated the presence of anxiety and depression. ${ }^{23}$

Questions related to transmission, vulnerable groups, signs, symptoms, and complications regarding COVID-19 were asked to assess the knowledge about COVID-19 disease in the third section. The responses were coded as "1" for correct response and " 0 " for an incorrect response for each question. The cumulative scores were segregated into three categories afterward, including inadequate knowledge ( $\leq 60 \%)$, intermediate knowledge (61-80\%), and good knowledge $(\geq 80 \%)$. This criterion has already been used in the literature. ${ }^{21}$

In the last section, the changes in dietary habits due to the COVID-19 disease situation were asked via closed-ended questions regarding the consumption of major food groups (increased, decreased, or not affected), including fast food, soft drinks, fruit juices and drinks, fruits and vegetables, meat, and proteins, added fats, and sugar and dairy products. The participants were also asked about the consumption of specific diet or bioactive components for immunity boosting.

A pilot study was conducted with a group of respondents (data excluded) to measure the internal consistency of the questionnaire, which was found to be in an acceptable range (>0.7).

Data collection procedure. All data were collected using an online, self-administered questionnaire developed via Google forms because of COVID-19 disease lockdown all over Punjab. The online questionnaire was disseminated to the target population via various media platforms, including Facebook and Whatsapp, and their responses were collected.

Ethical permission. This study was conducted according to the guidelines described in "Strengthening the Reporting of Observational Studies in Epidemiology: explanation and elaboration-2007." Online informed consent was obtained from all subjects/patients before getting the required information via Google forms and various social media platforms. In addition, ethics permission was obtained before the start of the study.

Data analysis. The collected data were analyzed using Statistical Package for Social Sciences version 25 (IBM, Armonk, NY). Level of significance was set at $P<0.1 \%$. The associations between knowledge regarding COVID-19 and demographic variables, anthropometric data, physical activity, and dietary habits were assessed using the chi-square test, and observed frequencies and percentages were calculated. Multiple linear regression was performed to assess the relationships among various demographic variables and COVID-19 knowledge. Odds ratios and Cls for the odds ratios were also calculated.

\section{RESULTS}

Of total $(N=1956)$, the majority of the participants $(55.4 \%)$ were between the age of $21-30$ years, were females $(72.1 \%)$, and had an undergraduate degree (67.6\%). Nearly $80 \%$ of the study participants $(79.1 \%)$ were unemployed and belonged to urban areas $(78.2 \%)$.

The physical activity of the participants was affected because of the COVID-19 lockdown as $66.9 \%$ of the participants had a decrease in physical activity and around $40 \%$ of the participants also gained weight because of COVID-19 lockdown (Table 1).

Only $7.4 \%$ of participants had good knowledge about COVID-19. The data show strong associations among various demographic variables, including age, gender, ethnicity, education, employment status, family income, and geographical location with a knowledge score regarding COVID-19 $(P<$ 0.05). With an increase in age, COVID-19-related knowledge 
TABLE 1

Demographic characteristics of study population $(N=1956)$

\begin{tabular}{|c|c|c|c|c|}
\hline Demographic variable & $n(\%)$ & Male, $n(\%)$ & Female, $n(\%)$ & $P$-value \\
\hline \multicolumn{5}{|l|}{ Age-group (years) } \\
\hline$<20$ & $759(38.8)$ & $102(18.7)$ & $657(46.6)$ & \multirow[t]{3}{*}{$<0.001$} \\
\hline $21-30$ & $1,083(55.4)$ & 348 (63.7) & 735 (52.1) & \\
\hline$>30$ & $114(5.8)$ & $96(17.6)$ & $18(1.3)$ & \\
\hline \multicolumn{5}{|l|}{ Ethnicity } \\
\hline Urdu & $1,119(57.2)$ & $228(41.8)$ & 891 (63.2) & \multirow[t]{3}{*}{$<0.001$} \\
\hline Punjabi & $606(31.0)$ & $147(26.9)$ & 459 (32.6) & \\
\hline Siraiki & 231 (11.8) & $171(31.3)$ & $60(4.3)$ & \\
\hline \multicolumn{5}{|l|}{ Education } \\
\hline Intermediate & $156(8.0)$ & $36(6.6)$ & $120(8.5)$ & \multirow[t]{3}{*}{$<0.001$} \\
\hline Undergraduate & $1,323(67.6)$ & $246(45.1)$ & 1,077 (76.4) & \\
\hline Postgraduate & 477 (24.4) & $264(48.4)$ & $213(15.1)$ & \\
\hline \multicolumn{5}{|l|}{ Employement status } \\
\hline Employed & 408 (20.9) & $246(45.1)$ & $162(11.5)$ & \multirow[t]{2}{*}{$<0.001$} \\
\hline Unemployed & $1,548(79.1)$ & $300(54.9)$ & $1,248(88.5)$ & \\
\hline \multicolumn{5}{|l|}{ Geographical location } \\
\hline Urban & $1,530(78.2)$ & $345(63.2)$ & $1,185(84.0)$ & \multirow[t]{2}{*}{$<0.001$} \\
\hline Rural & $426(21.8)$ & $201(36.8)$ & $225(16)$ & \\
\hline \multicolumn{5}{|l|}{ Family income } \\
\hline Nuclear & $1,287(65.8)$ & $258(47.3)$ & $1,029(73.0)$ & \multirow[t]{2}{*}{0.001} \\
\hline Joint & $1,083(34.2)$ & 288 (52.7) & $381(27.0)$ & \\
\hline \multicolumn{5}{|l|}{ Body mass index } \\
\hline Underweight & $261(13.3)$ & $33(6.0)$ & $228(16.2)$ & \multirow[t]{4}{*}{$<0.001$} \\
\hline Normal & $1,095(56.0)$ & 294 (53.8) & 801 (56.8) & \\
\hline Overweight & $429(21.9)$ & $165(30.2)$ & 264 (18.7) & \\
\hline Obese & $171(8.7)$ & $54(9.9)$ & $117(8.3)$ & \\
\hline \multicolumn{5}{|l|}{ Anxiety status } \\
\hline No & $567(29.0)$ & $189(34.6)$ & $378(26.8)$ & \multirow[t]{2}{*}{$0.001^{*}$} \\
\hline Yes & $1,389(71.0)$ & $357(65.4)$ & 1,032 (73.2) & \\
\hline \multicolumn{5}{|l|}{ Depression status } \\
\hline No & $939(48.0)$ & $300(54.9)$ & $639(45.3)$ & \multirow[t]{2}{*}{$<0.001$} \\
\hline Yes & 1,017 (52.0) & $246(45.1)$ & 771 (54.7) & \\
\hline \multicolumn{5}{|l|}{ COVID-19 knowledge } \\
\hline Poor (less than $60 \%$ points) & $633(32.4)$ & $150(27.5)$ & $483(34.3)$ & \multirow[t]{3}{*}{$<0.001$} \\
\hline $\begin{array}{l}\text { Intermediate (60 to less than } 80 \% \\
\text { points) }\end{array}$ & $1,179(60.3)$ & $330(60.4)$ & $849(60.2)$ & \\
\hline Good (80\% or more) & $144(7.4)$ & $66(12.1)$ & $78(5.5)$ & \\
\hline \multicolumn{5}{|c|}{ Effect of COVID-19 lockdown on physical activity } \\
\hline Increased & $210(10.7)$ & $60(11.0)$ & $150(10.6)$ & \multirow[t]{3}{*}{0.225} \\
\hline Decreased & $1,308(66.9)$ & 378 (69.2) & $930(66.0)$ & \\
\hline Not effected & 438 (22.4) & $108(19.8)$ & $330(23.4)$ & \\
\hline \multicolumn{5}{|l|}{ Effect of COVID-19 lockdown on weight } \\
\hline Increased & $759(38.8)$ & 225 (41.2) & $534(37.9)$ & \multirow{3}{*}{0.325} \\
\hline Decreased & 375 (19.2) & 96 (17.6) & 279 (19.8) & \\
\hline Not effected & $822(42.0)$ & $225(41.2)$ & $597(42.3)$ & \\
\hline
\end{tabular}

also increased as the maximum proportion of people having good knowledge (15.8\%) were from the age-group of $>30$ years compared with $2.8 \%$ ( $\leq 20$ years ago) and $9.7 \%$ (21-30 years of age). Male participants (good knowledge $=12.1 \%$ ) had more knowledge about COVID-19 than females (good knowledge $=5.5 \%$ ). Siraiki ethnic group (good knowledge $=13.0 \%$ ) (a local ethnic group within Punjab Province Pakistan) had significantly more knowledge than the other ethnic groups, including Urdu (good knowledge $=6.7 \%$ ) and Punjabi (good knowledge $=6.4 \%$ ). The participants having postgraduate education (good knowledge $=13.2 \%$ ) were more aware of the COVID-19 than other groups (good knowledge $=$ 5.4-5.8\%). Employed participants (good knowledge = $15.4 \%)$ were more educated regarding COVID-19 than unemployed (good knowledge $=5.2 \%$ ), and similarly, participants from urban settings were more aware of COVID-19 than rural locations. Overall, an inconsistent trend was observed among the family income and knowledge of COVID19 , but maximum knowledge was found in the highest family income groups (good knowledge $=10.9 \%$ ) (Table 2).
Around $70 \%$ of the participants were suffering from anxiety, and $52 \%$ were depressed because of the COVID-19 pandemic and lockdown. No association was found between anxiety status and COVID-19 knowledge. Depression status $\left(P ; 0.000^{\star}\right)$ and body mass index (BMI, $\left.P ; 0.001^{\star}\right)$ were found to be significantly associated with the knowledge score regarding COVID-19 $(P<0.05)$. Depressed participants $(4.7 \%$ good knowledge) had less knowledge than nondepressed participants (10.2\% good knowledge).

The BMI of $21.9 \%$ of participants was lower than the standard, as shown in Table 1. Participants having normal and obese BMI categories had more knowledge than overweight participants (Table 3 ). Consumption of fast foods, soft/cola drinks, fresh fruits, fresh/cooked vegetables, cooked meat (outside/homemade), milk and dairy products, sugar, and fats was found to have a significant association with the knowledge of COVID-19. The decrease in fast foods, soft/cola drinks and fruits, juices/drinks, cooked meat (outside the home), sugar, and fat consumption was associated with an increased level of knowledge 
TABLE 2

Association of demographic variables and knowledge regarding COVID-19

\begin{tabular}{|c|c|c|c|c|c|c|}
\hline \multicolumn{2}{|c|}{ Variable } & \multicolumn{3}{|c|}{ COVID-19 knowledge, $n(\%)$} & \multirow[b]{2}{*}{ Average knowledge score (\%) } & \multirow[b]{2}{*}{$P$-value } \\
\hline & Category & Poor & Intermediate & Good & & \\
\hline \multirow[t]{3}{*}{ Age-group (years) } & $\leq 20$ & $345(45.5)$ & $393(51.8)$ & $21(2.8)$ & 61 & $<0.001$ \\
\hline & $21-30$ & $273(25.2)$ & $705(65.1)$ & $105(9.7)$ & 68 & \\
\hline & $>30$ & $15(13.2)$ & $81(71.1)$ & $18(15.8)$ & 72 & \\
\hline \multirow[t]{2}{*}{ Gender } & Male & $150(27.5)$ & $330(60.4)$ & $66(12.1)$ & 68 & $<0.001$ \\
\hline & Female & $483(34.3)$ & 849 (60.2) & $78(5.5)$ & 65 & \\
\hline \multirow[t]{3}{*}{ Ethnicity } & Urdu & $414(37)$ & $630(56.3)$ & $75(6.7)$ & 64 & $<0.001$ \\
\hline & Punjabi & $183(30.2)$ & $384(63.4)$ & $39(6.4)$ & 66 & \\
\hline & Siraiki & $36(15.6)$ & $165(71.4)$ & $30(13)$ & 71 & \\
\hline \multirow[t]{3}{*}{ Education } & Intermediate & $54(34.6)$ & 93 (59.6) & $9(5.8)$ & 63 & $<0.001$ \\
\hline & Undergraduate & $483(36.5)$ & $768(58)$ & $72(5.4)$ & 64 & \\
\hline & Postgraduate & $96(20.1)$ & $318(66.7)$ & $63(13.2)$ & 70 & \\
\hline \multirow[t]{2}{*}{ Employment status } & Employed & $84(20.6)$ & $261(64)$ & $63(15.4)$ & 70 & $<0.001$ \\
\hline & Unemployed & $549(35.5)$ & 918 (59.3) & $81(5.2)$ & 64 & \\
\hline \multirow[t]{2}{*}{ Family type } & Nuclear & 432 (33.6) & 762 (59.2) & $93(7.2)$ & 65 & 0.278 \\
\hline & Joint & $201(30)$ & $417(62.3)$ & $51(7.6)$ & 66 & \\
\hline \multirow[t]{5}{*}{ Family income (PKR) } & $<20,000$ & 75 (30.9) & $162(66.7)$ & $6(2.5)$ & 66 & $<0.001$ \\
\hline & $21,000-40,000$ & $195(41.9)$ & $234(50.3)$ & $36(7.7)$ & 64 & \\
\hline & $41,000-60,000$ & 153 (40.2) & 207 (54.3) & $21(5.5)$ & 63 & \\
\hline & $61,000-80,000$ & $84(26.4)$ & $213(67)$ & $21(6.6)$ & 67 & \\
\hline & $>80,000$ & $126(23)$ & $363(66.1)$ & 60 (10.9) & 68 & \\
\hline \multirow[t]{2}{*}{ Geographical location } & Urban & $477(31.2)$ & $930(60.8)$ & $123(8)$ & 66 & 0.021 \\
\hline & Rural & $156(36.6)$ & 249 (58.5) & 21 (4.9) & 64 & \\
\hline
\end{tabular}

about COVID-19, but the poor knowledge category results was inconsistent with healthy dietary changes. An increase in fresh fruits', fresh vegetables'/cooked, cooked meat (homemade), and milk and dairy products' consumption was associated with an increased level of knowledge. All healthy changes in diet were associated with an increased level of knowledge about COVID-19. The usage of vitamin C and supplements for immunity boosting purposes was associated with a lower proportion of poor knowledge regarding coronavirus 2019 (Table 4).

The combined effect of all predictor variables was 80.21. Except for family type, all predictor variables had a significant association with COVID-19 knowledge score. By moving from male to female, the COVID-19 knowledge score decreases by 1.862 points from the combined effect $\left(P\right.$-value $0.006^{\star}, \mathrm{Cl}$ : 75.973-84.448). From employed participants to unemployed ones, the COVID-19 knowledge score decreases by 5.432 points from the combined effect $\left(P\right.$-value $0.000^{*}, \mathrm{Cl}:-3.201$ to -0.524$)$. Changing geographical location from urban to rural, the COVID-19 knowledge score decreases by 2.412 points from the combined effect $\left(P\right.$-value $0.000^{*}, \mathrm{Cl}:-3.761$ to -1.063$)$. By moving the status of depression from negative to positive, the COVID-19 knowledge score decreases by 2.02 points from the combined effect $\left(P\right.$-value $0.002^{*}, \mathrm{Cl}:-3.291$ to -0.75 ) (Table 5).

\section{DISCUSSION}

The present study was conducted among the general public of Punjab, Pakistan, to assess the knowledge of COVID-19 disease and its association with anxiety and depression, dietary habits, and physical activity during the COVID-19 lockdown. This study revealed that one-third of the participants had intermediate knowledge about COVID-19, around 78\% had anxiety, and half of them were depressed. Changes in dietary habits were associated with higher knowledge regarding COVID-19, and depression disorder was inversely associated with COVID-19 knowledge.

Fear of death and extinction of humanity, loneliness, isolation at home, and sadness contribute to psychological and depressive disorders. ${ }^{24,25}$ The findings of this study suggested that around one-third of the participants were suffering from anxiety and one-fifth were having depressive symptoms due to the COVID-19 outbreak/lockdown, but the response was the same in both males and females. ${ }^{26}$ We found fourth/ fifth of the study population with anxiety, and around $50 \%$

TABLE 3

Association of anxiety, depression, and body mass index with knowledge regarding COVID-19

\begin{tabular}{|c|c|c|c|c|c|c|}
\hline \multicolumn{2}{|c|}{ Variables } & \multicolumn{3}{|c|}{ COVID-19 knowledge, $n$ (\%) } & \multirow[b]{2}{*}{ Average knowledge score (\%) } & \multirow[b]{2}{*}{$P$-value } \\
\hline & Categories & Poor & Intermediate & Good & & \\
\hline \multirow[t]{2}{*}{ Anxiety status } & Normal & $183(32.3)$ & $336(59.3)$ & $48(8.5)$ & 65 & 0.482 \\
\hline & Anxiety & $450(32.4)$ & $843(60.7)$ & $96(6.9)$ & 66 & \\
\hline \multirow[t]{2}{*}{ Depression status } & Normal & $276(29.4)$ & $567(60.4)$ & $96(10.2)$ & 67 & $<0.001$ \\
\hline & Depression & 357 (35.1) & 612 (60.2) & $48(4.7)$ & 65 & \\
\hline \multirow[t]{4}{*}{ Body mass index } & Underweight & $96(36.8)$ & $156(59.8)$ & $9(3.4)$ & 64 & 0.001 \\
\hline & Normal & 366 (33.4) & $633(57.8)$ & $96(8.8)$ & 66 & \\
\hline & Overweight & $126(29.4)$ & $282(65.7)$ & $21(4.9)$ & 65 & \\
\hline & Obese & 45 (26.3) & 108 (63.2) & $18(10.5)$ & 66 & \\
\hline
\end{tabular}


TABLE 4

Association of dietary habits and knowledge regarding COVID-19

\begin{tabular}{|c|c|c|c|c|c|c|}
\hline \multirow[b]{2}{*}{ Consumption of various foods } & \multirow[b]{2}{*}{ Categories } & \multirow[b]{2}{*}{ Overall, $n(\%)$} & \multicolumn{3}{|c|}{ COVID-19 knowledge, $n(\%)$} & \multirow[b]{2}{*}{$P$-value } \\
\hline & & & Poor & Intermediate & Good & \\
\hline \multirow[t]{3}{*}{ Fast foods } & Increased & $231(11.8)$ & 63 (27.2) & $159(68.8)$ & $9(3.8)$ & $0.004^{*}$ \\
\hline & Decreased & $1,380(70.6)$ & $468(33.9)$ & $813(58.9)$ & $99(7.1)$ & \\
\hline & Not affected & $345(17.6)$ & $102(29.5)$ & $207(60)$ & $36(10.4)$ & \\
\hline \multirow[t]{3}{*}{ Soft drinks/cola drinks } & Increased & 315 (16.1) & $96(30.4)$ & $210(66.6)$ & $9(2.8)$ & $0.008^{*}$ \\
\hline & Decreased & $1,158(59.2)$ & $384(33.1)$ & $678(58.5)$ & 96 (8.2) & \\
\hline & Not affected & $483(24.7)$ & $153(31.6)$ & $291(60.2)$ & 39 (8) & \\
\hline \multirow[t]{3}{*}{ Fruit juices and fruit drinks } & Increased & $1,059(54.1)$ & $357(33.7)$ & $633(59.7)$ & $69(6.5)$ & 0.312 \\
\hline & Decreased & $387(19.8)$ & $114(29.4)$ & $243(62.7)$ & $30(7.7)$ & \\
\hline & Not affected & $510(26.1)$ & $162(31.7)$ & $303(59.4)$ & $45(8.8)$ & \\
\hline \multirow[t]{3}{*}{ Bakery items } & Increased & 318 (16.3) & $90(28.3)$ & $198(62.2)$ & $30(9.4)$ & 0.307 \\
\hline & Decreased & $1,074(54.9)$ & $360(33.5)$ & $642(59.7)$ & $72(6.7)$ & \\
\hline & Not affected & $564(28.8)$ & $183(32.4)$ & $339(60.1)$ & $42(7.4)$ & \\
\hline \multirow[t]{3}{*}{ Fresh fruits } & Increased & $1,275(65.2)$ & $393(30.8)$ & $771(60.4)$ & $111(8.7)$ & $0.007^{\star}$ \\
\hline & Decreased & $288(14.7)$ & $111(38.5)$ & 165 (57.2) & $12(4.1)$ & \\
\hline & Not affected & $393(20.1)$ & $129(32.8)$ & $243(61.8)$ & $21(5.3)$ & \\
\hline \multirow[t]{3}{*}{ Fresh vegetables/cooked } & Increased & $1,242(63.5)$ & $396(31.8)$ & $738(59.4)$ & $108(8.6)$ & $0.001^{*}$ \\
\hline & Decreased & $171(8.7)$ & $45(26.3)$ & $123(71.9)$ & $3(1.7)$ & \\
\hline & Not affected & $543(27.8)$ & 192 (35.3) & 318 (58.5) & $33(6.1)$ & \\
\hline \multirow[t]{3}{*}{ Cooked meat outside } & Increased & $501(25.6)$ & 147 (29.3) & $315(62.8)$ & $39(7.7)$ & $0.014^{\star}$ \\
\hline & Decreased & $831(42.5)$ & $267(32.1)$ & 489 (58.8) & 75 (9) & \\
\hline & Not affected & 624 (31.9) & 219 (35.1) & $375(60.1)$ & $30(4.8)$ & \\
\hline \multirow[t]{3}{*}{ Cooked meat homemade } & Increased & $1,059(54.1)$ & $336(31.7)$ & $630(59.4)$ & $93(8.7)$ & $0.019^{\star}$ \\
\hline & Decreased & 234 (12.0) & $84(35.8)$ & $144(61.5)$ & $6(2.5)$ & \\
\hline & Not affected & 663 (33.9) & $213(32.1)$ & $405(61.1)$ & $45(6.7)$ & \\
\hline \multirow[t]{3}{*}{ Milk and dairy products } & Increased & $930(47.5)$ & $297(31.9)$ & $576(61.9)$ & $57(6.1)$ & $<0.001^{*}$ \\
\hline & Decreased & $189(9.7)$ & 93 (49.2) & $90(47.6)$ & $6(3.1)$ & \\
\hline & Not affected & $837(42.8)$ & $243(29)$ & $513(61.3)$ & $81(9.6)$ & \\
\hline \multirow{3}{*}{ Sugar and fats } & Increased & 663 (33.9) & $231(34.8)$ & $390(58.8)$ & $42(6.3)$ & $0.023^{*}$ \\
\hline & Decreased & $522(26.7)$ & $141(27)$ & $342(65.5)$ & $39(7.4)$ & \\
\hline & Not affected & 771 (39.4) & $261(33.8)$ & 447 (57.9) & $63(8.1)$ & \\
\hline \multirow[t]{2}{*}{ Taking vitamin $\mathrm{C}$ for immunity boosting } & Yes & $810(41.4)$ & $222(27.4)$ & $531(65.6)$ & $57(7)$ & $<0.001^{*}$ \\
\hline & No & $1,146(58.6)$ & 411 (35.9) & $648(56.5)$ & $87(7.6)$ & \\
\hline \multirow[t]{2}{*}{ Taking immunity-boosting supplement } & Yes & $414(21.2)$ & $105(25.4)$ & $288(69.6)$ & $21(5.1)$ & $<0.001^{*}$ \\
\hline & No & $1,542(78.8)$ & 528 (34.2) & $891(57.8)$ & $123(8)$ & \\
\hline \multirow[t]{3}{*}{ Source of food in COVID-19 lockdown } & Homemade & $1,443(73.8)$ & $477(33.1)$ & $849(58.8)$ & $117(8.1)$ & $0.042^{*}$ \\
\hline & Ordered food from outside & $24(1.2)$ & $9(37.5)$ & $12(50)$ & $3(12.5)$ & \\
\hline & Both & $489(25.0)$ & $147(30.1)$ & $318(65)$ & $24(4.9)$ & \\
\hline \multirow[t]{4}{*}{ Food ordered in COVID-19 lockdown } & Conventional/desi foods & $300(15.3)$ & $87(29)$ & $189(63)$ & $24(8)$ & 0.098 \\
\hline & Fast foods & $288(14.7)$ & $105(36.5)$ & $162(56.3)$ & $21(7.3)$ & \\
\hline & Both & 408 (20.9) & $111(27.2)$ & $264(64.7)$ & $33(8.1)$ & \\
\hline & Not applicable & 960 (49.1) & $330(34.4)$ & 564 (58.8) & $66(6.9)$ & \\
\hline
\end{tabular}

${ }^{\star}$ Significant association.

were depressive. Like previous studies, females in our study population were more depressed and anxious than males. ${ }^{27}$

The COVID-19-related knowledge of the survey participants had a significant association with age, gender, education, and place of residence, which is in accordance with a previous study conducted in Pakistan and Jordan. ${ }^{21,22}$
Another study conducted to assess knowledge, attitudes, practice, and misconceptions related to COVID-19 showed an inverse association between age and COVID-19 knowledge $\left(P\right.$-value $\left.0.037^{*}\right)$. ${ }^{28,29}$

A study conducted in Palestine showed an increase in weight in $41.7 \%$ of participants, and physical activity was

TABLE 5

Multiple linear regression for knowledge about COVID-19

\begin{tabular}{|c|c|c|c|c|c|c|c|}
\hline & \multicolumn{2}{|c|}{$\begin{array}{l}\text { Unstandardized } \\
\text { coefficients }\end{array}$} & \multirow{2}{*}{$\frac{\text { Standardized coefficients }}{\text { Beta }}$} & \multirow[b]{2}{*}{$t$-value } & \multirow[b]{2}{*}{ Sig. } & \multicolumn{2}{|c|}{$95.0 \% \mathrm{Cl}$ for beta } \\
\hline & B & SE & & & & Lower bound & Upper bound \\
\hline Constant & 80.211 & 2.161 & & 37.123 & $<0.001^{*}$ & 75.973 & 84.448 \\
\hline Gender & -1.862 & 0.683 & -0.067 & -2.728 & $0.006^{\star}$ & -3.201 & -0.524 \\
\hline Employment & -5.432 & 0.738 & -0.178 & -7.356 & $<0.001^{*}$ & -6.88 & -3.984 \\
\hline Geographical location & -2.412 & 0.688 & -0.08 & -3.507 & $<0.001^{*}$ & -3.761 & -1.063 \\
\hline Family type & 0.075 & 0.602 & 0.003 & 0.125 & 0.901 & -1.106 & 1.257 \\
\hline Anxiety & 2.423 & 0.704 & 0.089 & 3.441 & $0.001^{*}$ & 1.042 & 3.804 \\
\hline Depression & -2.02 & 0.648 & -0.081 & -3.118 & $0.002^{*}$ & -3.291 & -0.75 \\
\hline
\end{tabular}

Knowledge regarding COVID-19 (\%) was predicted by various binary variables, including gender (male/female), employment (employed/unemployed), geographical location (urban/rural), family type (nuclear/joint), anxiety (no/yes), and depression (no/yes).

* Significant association. 
reduced in $39.8 \%$ of the female participants owing to COVID19 lockdown. $^{30}$ Compared with these findings, our study showed that three-fourth of the participants experienced a decreasing trend in physical activity, and $38.9 \%$ had gained weight during the lockdown (Table 1). Prolonged confinement and restricted movement may have adverse effects on human health, including weight gain, irregular sleep, changes in dietary habits, and loss of cardiorespiratory fitness. ${ }^{31}$ Furthermore, previous studies have also shown a link of weight gain with food insecurity, persistent stay at home, and physical inactivity. ${ }^{32}$ According to a cohort study, mood changes (anxiety and depression) are associated with elevated BMI, mediated by poor dietary habits and lifestyle habits. ${ }^{33}$

A study conducted to assess the impact of COVID-19 lockdown reported a decrease in sugar-added drinks (26.2\%), an increase in vegetable intake by $39.5 \%$, fruits intake by $33.2 \%$, dairy products by $33.2 \%$, fried foods by $36.7 \%$, and sweets intake by $46.5 \% .^{30}$ Similarly, in the present study, fast food consumption was decreased by $70.6 \%$, soft drinks by $59.2 \%$, fruits juices/drinks increased by $54.1 \%$, fresh fruits by $65.2 \%$, vegetables by $63.5 \%$, and milk and dairy products by $47.5 \%$. The consumption of sugar and fats was also increased by $33.9 \%$. However, all these positive changes were significantly associated with an increased good level of COVID-19-related knowledge.

All previous studies only focused on assessing the knowledge of COVID-19 and stress dietary and lifestyle changes induced by COVID-19 lockdown individually. However, our study's novelty is that we assessed not only all these parameters together but also the relation of anxiety, depression, dietary, and lifestyle changes with the knowledge of COVID-19 in the adult population. The current manuscript demands comprehensive educational programs for COVID-19-related knowledge, nutrition education, and stress management to manage the consequences related to COVID-19 among the general public of Pakistan.

The authors acknowledge certain limitations of this study. First, the data were collected using a convenience sampling method which may cause response bias, and the results could not be generalized to the whole Pakistani population. Second, the questionnaire was disseminated through various social media networking websites; therefore, only participants with access to the Internet and social media participated in this study. Most of the young population in Pakistan are aware and familiar with the use of the Internet and social media; therefore, more than half of our study participants were young. However, our study is unable to get a response from other vulnerable populations such as older adults. Third, our research is based on self-reported data; therefore, participants may provide more socially acceptable answers rather than being truthful. A study with a large sample size covering participants with different age-groups using a random sampling approach is needed to warrant our study's findings.

This study concludes that the knowledge about the COVID19 pandemic of most of the study population is intermediate. The COVID-19 lockdown and pandemic have significantly increased the level of anxiety and depression among the survey participants. Dietary habits have also been affected by this lockdown, and people reported more willingness to consume foods that have a positive impact on the immunity of the peoples. Furthermore, knowledge about COVID-19 was found to be associated with depression, BMI, and changes in dietary habits.
The unprecedented COVID-19 pandemic has brought changes in the living style of almost every human being. Our study provides baseline information about the impact of COVID-19 lockdown on dietary habits, anxiety, and depression in Pakistani population that can help formulate concrete policy-making for the Pakistani population in terms of public health prospects. Mass-level educational programs should be launched via print and electronic media to enhance public awareness about COVID-19 and to improve dietary behavior of people. Furthermore, telehealth services should be initiated to help people to cope with their mental health issues.

Received November 10, 2020. Accepted for publication February 28, 2021.

Published online March 9, 2021.

Acknowledgments: We would like to thank all the participants of the study. The American Society of Tropical Medicine and Hygiene has waived the Open Access fee for this article due to the ongoing COVID19 pandemic and has assisted with publication expenses.

Authors' addresses: Ahmad Ali, Muhammad Sohaib, Sanaullah Iqbal, and Azmat Ullah Khan, Department of Food Science and Human Nutrition, University of Veterinary and Animal Sciences, Lahore, Pakistan, E-mails: ahmad.ali@uvas.edu.pk, muhammad. sohaib@uvas.edu.pk, sanaullah.iqbaal@uvas.edu.pk, and azmat. khan@uvas.edu.pk. Khezar Hayat, Pharmacy Administration and Clinical Pharmacy, Xian Jiaotong University, Xi'an, China, and Institute of Pharmaceutical Sciences, University of Veterinary and Animal Sciences, Lahore, Pakistan, E-mail: khezar.hayat@uvas.edu.pk. Muhammad Fawad Rasool, Department of Pharmacy Practice, Bahauddin Zakariya University, Multan, Pakistan, E-mail: fawadrasool@ bzu.edu.pk.

This is an open-access article distributed under the terms of the Creative Commons Attribution (CC-BY) License, which permits unrestricted use, distribution, and reproduction in any medium, provided the original author and source are credited.

\section{REFERENCES}

1. Bedford $J$ et al., 2020. COVID-19: towards controlling of a pandemic. Lancet 395: 1015-1018.

2. Gao J, Tian Z, Yang X, 2020. Breakthrough: chloroquine phosphate has shown apparent efficacy in treatment of COVID-19 associated pneumonia in clinical studies. Biosci Trends 14: 72-73.

3. Government of Pakistan, 2020. COVID-19 Dashboard; Government of Pakistan. Available at: http://covid.gov.pk/stats/ pakistan. Accessed June 21, 2020.

4. WHO, 2020. Coronavirus Disease (COVID-19) Pandemic. Geneva, Switzerland: World Health Organization. Available at: https:// www.who.int/emergencies/diseases/novel-coronavirus-2019. Accessed June 21, 2020.

5. Team C,2020. Severe outcomes among patients with coronavirus disease 2019 (COVID-19)-United States, February 12-March 16, 2020. MMWR Morb Mortal Wkly Rep 69: 343-346.

6. Pappaioanou M, Gramer M, 2010. Lessons from pandemic H1N1 2009 to improve prevention, detection, and response to influenza pandemics from a one health perspective. ILAR J 51: 268-280.

7. Maffetone PB, Laursen PB, 2020. The perfect storm: coronavirus (COVID-19) pandemic meets overfat pandemic. Front Public Health 8: 135.

8. Di Renzo L et al., 2020. Eating habits and lifestyle changes during COVID-19 lockdown: an Italian survey. J Trans/ Med 18: 229.

9. Giacalone D, Frøst MB, Rodríguez-Pérez C, 2020. Reported changes in dietary habits during the COVID-19 lockdown in the Danish population: the Danish COVIDiet study. Front Nutr 7: 592112. 
10. Di Renzo L et al., 2020. Psychological aspects and eating habits during COVID-19 home confinement: results of EHLC-COVID19 Italian online survey. Nutrients 12: 2152.

11. Kumar A, Somani A, 2020. Dealing with corona virus anxiety and OCD. Asian J Psychiatr 51: 102053.

12. Taylor CT, Pearlstein SL, Kakaria S, Lyubomirsky S, Stein MB, 2020. Enhancing social connectedness in anxiety and depression through amplification of positivity: preliminary treatment outcomes and process of change. Cognit Ther Res 44: 788-800.

13. Xu F, Chong BQ, Cai T, Zhang JL, Lv J, 2020. Associations between major dietary patterns and anxiety in middle-aged adults in eastern China. Public Health Nutr 15: 1-9.

14. Hammond KA, Mahan LK, 2017. Intake: analysis of the diet. Krause's Food and the Nutrition Care Process. Amsterdam, Netherlands: Elsevier, 53.

15. Cordain L, Eaton SB, Sebastian A, Mann N, Lindeberg S, Watkins BA, O'Keefe JH, Brand-Miller J, 2005. Origins and evolution of the western diet: health implications for the 21st century. Am J Clin Nutr 81: 341-354.

16. Eder W, Ege MJ, von Mutius E, 2006. The asthma epidemic. N Engl J Med 355: 2226-2235.

17. Bach JF, 2002. The effect of infections on susceptibility to autoimmune and allergic diseases. N Engl J Med 347: 911-920.

18. Wypych TP, Marsland BJ, Ubags ND, 2017. The impact of diet on immunity and respiratory diseases. Ann Am Thorac Soc 14: S339-S347.

19. Vandenbroucke JP, Von Elm E, Altman DG, Gøtzsche PC, Mulrow CD, Pocock SJ, Poole C, Schlesselman JJ, Egger M, Initiative $S, 2007$. Strengthening the reporting of observational studies in epidemiology (STROBE): explanation and elaboration. PLOS Med 4: e297.

20. Kish L, 1995. Survey Sampling. Hoboken, NJ: Wiley-Interscience.

21. Olaimat AN, Aolymat I, Shahbaz HM, Holley RA, 2020. Knowledge and information sources about COVID-19 among university students in Jordan: a cross-sectional study. Front Public Health 8: 254.

22. Hayat K, Rosenthal M, Xu S, Arshed M, Li P, Zhai P, Desalegn GK, Fang Y, 2020. View of Pakistani residents toward coronavirus disease (COVID-19) during a rapid outbreak: a rapid online survey. Int J Environ Res Public Health 17: 3347.
23. Mumford DB, Ayub M, Karim R, Izhar N, Asif A, Bavington JT, 2005. Development and validation of a questionnaire for anxiety and depression in Pakistan. J Affect Disord 88: 175-182.

24. Hiscott J, Alexandridi M, Muscolini M, Tassone E, Palermo E, Soultsioti M, Zevini A, 2020. The global impact of the coronavirus pandemic. Cytokine Growth Factor Rev 53: 1-9.

25. Brooks SK, Webster RK, Smith LE, Woodland L, Wessely S, Greenberg N, Rubin GJ, 2020. The psychological impact of quarantine and how to reduce it: rapid review of the evidence. Lancet 395: 912-920.

26. Huang Y, Zhao N, 2020. Generalized anxiety disorder, depressive symptoms and sleep quality during COVID-19 outbreak in China: a web-based cross-sectional survey. Psychiatry Res 28: 112954.

27. Al-Rabiaah A, Temsah MH, Al-Eyadhy AA, Hasan GM, Al-Zamil F, Al-Subaie S, Alsohime F, Jamal A, Alhaboob A, Al-Saadi B, 2020. Middle East Respiratory Syndrome-Corona Virus (MERS-CoV) associated stress among medical students at a university teaching hospital in Saudi Arabia. J Infect Public Health 13: 687-769.

28. Baig M, Jameel T, Alzahrani SH, Mirza AA, Gazzaz ZJ, Ahmad T, Baig F, Almurashi SH, 2020. Predictors of misconceptions, knowledge, attitudes, and practices of COVID-19 pandemic among a sample of Saudi population. PloS one 15: e0243526.

29. Azlan AA, Hamzah MR, Sern TJ, Ayub SH, Mohamad E, 2020. Public knowledge, attitudes and practices towards COVID-19: a cross-sectional study in Malaysia. PLoS One 15: e0233668.

30. Allabadi H, Dabis J, Aghabekian V, Khader A, Khammash U, 2020. Impact of COVID-19 lockdown on dietary and lifestyle behaviours among adolescents in Palestine. Dynamic Hum Health 7: $1-11$.

31. Wang G, Zhang Y, Zhao J, Zhang J, Jiang F, 2020. Mitigate the effects of home confinement on children during the COVID-19 outbreak. Lancet 395: 945-947.

32. Cluver L et al., 2020. Parenting in a time of COVID-19. Lancet 395: e64.

33. Sahle BW, Breslin M, Sanderson K, Patton G, Dwyer T, Venn A, Gall S, 2019. Association between depression, anxiety and weight change in young adults. BMC Psychiatry 19: 398. 